\title{
ENGAJAMENTO ESTUDANTIL DA EDUCAÇÃO A DISTÂNCIA POR MEIO DO PROGRAMA DE PERMANÊNCIA ACADÊMICA - PROPAC.
}

\author{
SÃO PAULO/SP MAIO/2018
}

\author{
Danilo Santiago Gomes Valentim - EAD Laureate - dsvalentim@eadlaureate.com.br \\ Roberta Auler Bittencourt Bernardo - EAD Laureate - roberta.bernardo@eadlaureate.com.br \\ Luiz Demétrius Regly - EAD Laureate - luiz.rocha@eadlaureate.com.br
}

Tipo: Relato de Experiência Inovadora (EI)

Categoria: Conteúdos e Habilidades

Setor Educacional: EDUCAÇÃO SUPERIOR

\begin{abstract}
RESUMO
O presente artigo busca uma leitura do engajamento estudantil no ensino à distância $(E a D)$ e propõe que o estudante esteja emocionalmente conectado e satisfeito com o curso e a proposta da instituição resultando no melhor aprendizado. Descrevemos como os estudantes se comportam na interação sistêmica do Programa de Permanência Acadêmica - PROPAC embasado nos elementos de engajamento na Educação online de uma rede de instituição de ensino. A utilização da metodologia ativa, na qual o discente é capaz de auto gerir-se e governar seu processo de formação, é demonstrada por meio da pesquisa e metodologia quantitativa. Para atender essa abordagem, foram analisadas as entregas das atividades da rede. Dado que as entregas das atividades por parte dos estudantes foram constantes ao longo do período analisado, em algum momento ocorreu um desnível quantitativo, onde, para determinada atividade, o índice participativo foi inferior aos anteriores. Desta forma, buscou-se analisar, se em algum momento o fator engajamento foi comprometido, quais foram os fatos geradores, e a partir daí os planos de ação realizados.
\end{abstract}

Palavras-chave: Engajamento estudantil. Ensino a Distância (EaD). Estudante online. Metodologia Ativa. Permânencia Acadêmica. 


\section{INTRODUÇÃO}

De acordo com Reyes, Brackett, Rivers, Whitee Salovey (2012), o engajamento estudantil exige um envolvimento escolar com atividades de propósito educacional, portanto, é mais do que um estudante ouve e faz; considerando-se assim, uma conexão emocional e satisfação com o processo de aprendizado. O envolvimento dos estudantes está relacionado com aspectos emocionais, comportamentais e cognitivos, que visam o domínio dos trabalhos, estimulando sua curiosidade e integração acadêmica. É importante identificar os indicadores de engajamento dos estudantes especialmente nos cursos on-line, permitindo às universidades uma mensuração que pode ser utilizada no aprimoramento das práticas existentes (BEER, 2010). O Sistema de Aprendizagem Gerencial (Learning Management System- LMS), tem melhorado o ambiente em que os estudantes online se envolvem em seus estudos, pois mesmo que não ocorra o contato tradicional presencial, proporciona um processo interativo e também criativo com os tutores e professores. O controle de presença - hoje reformulado no lugar do aspecto presencial e físico - considera então, o avanço nas atividades realizadas por parte do estudante no ambiente virtual de aprendizagem (AVA). Dado que a presencialidade tida até então como referência do modelo tradicional em sala de aula; como é demonstrado o engajamento dos estudantes na educação à distância (EAD) de uma rede de instituição de ensino pelo programa de permanência acadêmica?

As medidas tradicionais do envolvimento dos estudantes, como a frequência das aulas, podem não ser mensuráveis, aplicando uma vez que nos cursos on-line muitas vezes não há necessidade de comparecer em determinado local ou em determinado horário (DOUGLAS \& ALEMANNE, 2007).

Embora a frequência das aulas seja medida pelas atividades realizadas, entende-se que é apenas um indicador de participação e não considera necessariamente a qualidade da participação. Nos cursos on-line a interação é assimétrica, e a participação pode ser definida por atividades síncronas como logs em sessões nas aulas de webconferências, participação nos fóruns de discussão e acesso aos materiais referenciais. Esses dados podem ser usados pelo corpo docente e tutorial, para estimular e aprimorar o envolvimento dos estudantes, que por sua vez, podem aumentar sua exigência com relação às IE's prestadoras, seus respectivos cursos, bem como as disciplinas. Os estudantes que exigem orientação substancial do instrutor, podem ter problemas com o ambiente assíncrono, o que exige um certo nível de disciplina (BULLEN, 2007).

A participação pode ser vista como um indicador de comportamento ativado pela motivação do estudante $e$ mensurável na educação on-line, embora com as mesmas limitações quanto à qualidade da participação. Embora a participação seja evidentemente um aspecto importante do envolvimento dos estudantes, o engajamento é uma construção ampla que abrange mais do que apenas a participação (BEER, 2010). 
O objetivo geral deste estudo é descrever como os estudantes se comportam na interação sistêmica que resulta nos apontamentos de engajamento a partir da realização das atividades avaliativas consideradas para cada período, tido como bloco de atividades e motivadas pelo Corpo Docente e Tutorial por meio do Programa de Permanência Acadêmica - Propac. Uma série de variáveis que influenciam o envolvimento dos estudantes em cursos on-line são identificados a partir da literatura e avaliados de acordo com dados institucionais para determinar sua influência no envolvimento dos estudantes on-line (BEER, 2010). Consideramos a interação da instituição educacional (IES) com a necessidade da aprendizagem do estudante a partir da consciência capacitadora deste, como forma de garantir condições suficientemente estruturadas para o aprendizado de máxima qualidade, premissa do tripé: pesquisa, extensão e diminuição da evasão. Nota-se considerável aumento dos estudantes que procuram cursos de ensino a distância nos últimos anos, devido aspectos de locomoção, flexibilidade dos horários e acessibilidade financeira. De acordo com o Censo da Educação Superior de 2016, do INEP, enquanto o ensino presencial teve queda anual de 0,08\% nas matrículas, o ensino a distância (EAD) teve expansão de 7,2\%.

\section{FUNDAMENTAÇÃO TEÓRICA}

De acordo com Times (2017), o engajamento é definido como o grau de atenção, curiosidade, interesse, otimismo e paixão que os estudantes têm quando estão estudando ou aprendendo; o que se estende ao nível da motivação que eles demonstram para aprender e progredir em sua educação. $\mathrm{O}$ conceito de "engajamento do estudante" está em consonância com o tempo dedicado e esforço realizado. Por outro lado, a ausência dessa inspiração e estímulo se gerado pela IES, tende a trazer sofrimento, deixando os estudantes, entediados, desapaixonados e insatisfeitos. Chen, Gonyea e Kuh (2008) consideram o grau em que os estudantes estão conectados com suas atividades educacionais, sendo o engajamento positivamente ligado a uma série de resultados desejados, incluindo notas altas, satisfação do estudante e perseverança.

\subsection{EDUCAÇÃO A DISTANCIA}

\subsubsection{Categorização}

De acordo com a ABED (2016), observamos algumas categorias de cursos a distância no Brasil, que, credenciados, são oferecidos por instituições autorizadas por órgão regulador federal, estadual ou municipal, em que a presença do estudante é exigida exclusivamente para avaliações de aprendizagem. A distância são cursos que têm a $100 \%$ da carga de disciplinas a distância. Um curso semipresencial deve ter até $20 \%$ 
de sua carga de trabalho oferecida na modalidade de ensino a distância. O ensino não corporativo aberto, são cursos que não são regulados por um órgão educacional, e oferecidos ao público em geral e podem ou não estar vinculados a uma instituição. $O$ aberto corporativo não é regularizado por um corpo educacional, e é projetado para atender às necessidades de treinamento de funcionários ou clientes de uma organização.

\subsubsection{Metodologia Ativa}

Atualmente, os meios de comunicação estão potencializados pelo avanço das novas tecnologias e pela percepção do mundo como uma rede de relações dinâmicas e em constante transformação, tem-se discutido a necessidade de urgentes mudanças nas instituições de ensino visando, entre outros aspectos, à reconstrução de seu papel social (FREIRE, 2006).

O processo de ensino-aprendizagem tem se restringido muitas vezes, à reprodução do conhecimento, no qual o docente assume o papel de transmissor de conteúdo, de modo que cabe ao aluno o processo de reter e repetir os mesmos, em uma atitude passiva e receptiva (ou reprodutora), tornando-se mero expectador, sem a necessária crítica e reflexão (BEHRENS, 2005).

Considerando-se, que a formação do estudante dura alguns anos, enquanto a atividade profissional pode permanecer por décadas, e os conhecimentos e competências vão se transformando velozmente, torna-se primordial pensar em uma metodologia para uma prática de educação libertadora, na formação de um profissional ativo e apto a aprender a aprender. Concomitantemente, a passagem da consciência ingênua para a consciência crítica requer a curiosidade criativa, indagadora e insatisfeita de um sujeito ativo, que reconhece a realidade como mutável, definido por Freire (2006), por isso a condição da metodologia ativa propor um direcionamento aos aspectos autônomos dos estudantes na consciência capacitativa deste como condição essencial ao processo de aperfeiçoamento acadêmico em sua interação no aprendizado que se traduzam também na vida social e profissional.

\subsubsection{Programa de Permanência Acadêmica (PROPAC)}

O Programa de Permanência Acadêmica (PROPAC) é embasado nos elementos do engajamento e está ligado a satisfação, motivação e resiliência do estudante de educação a distância de uma rede de ensino. Para Coates (2007), a motivação é um indicador de comportamento e está ligada ao engajamento abrangendo a aprendizagem ativa e colaborativa, atividades desafiadoras, comunicação contínua entre discentes e o corpo docente e tutorial, permanência acadêmica, experiências educacionais e apoio da 
comunidade de aprendizado, e também garante retenção e aumento de matrículas.

Os objetivos do programa são o sucesso acadêmico por meio de persistência do estudante, diminuição de gaps, análise da performance acadêmica, formação complementar. Também orientação e retenção como reprovação (DPs), necessidades especiais, e pedidos de cancelamento. Por fim, identificação de riscos, na entrada da plataforma, tempo de permanência, realização das atividades on-line, participação nos encontros presenciais e webconferências.

A instituição em seu papel de reforçar os processos que estimulem o engajamento, considera o uso de outras ferramentas de comunicação como Facebook, Short Message Service - SMS, Aplicativos, Whatsapp, Ações de ligação, Fórum Fale com o Professor, email, e videoconferências.

\section{METODOLOGIA DE PESQUISA}

Trata-se este, de um estudo de metodologia quantitativa. Ensina Minayo (1993, p. 102) que nesse tipo de pesquisa "busca-se um critério de representatividade numérica que possibilite a generalização dos conceitos teóricos que se quer testar". Para atender essa abordagem, foram utilizadas as informações dos cursos de graduação referente as entregas das atividades de uma rede de ensino. A observação se deu na entrega das 4 atividades dos estudantes que compõem a primeira nota (valendo 10 pontos, e fracionadas em 2,5 pontos cada), gravadas na plataforma Blackboard LMS, no ano letivo de 2017.

\section{ANÁLISE DE RESULTADOS}

Por não contar diretamente com a figura do professor, o EAD costuma exigir dos estudantes que capacidades como autonomia e autodeterminação estejam mais desenvolvidas do que em estudantes do modelo convencional. O desempenho está diretamente ligado ao grau de dedicação do estudante, por isso em alguns pontos, o método de ensino à distância é mais rígido que o tradicional ensino presencial. O EAD propõe que o estudante realize suas atividades subsidiados de elementos que reforcem o aprendizado, não esquecendo a importância de disciplinar-se, tendo momentos de dedicação destinados à leitura, observação de materiais referenciais e complementares e realização das tarefas. Acompanhamos as entregas das atividades 1, 2, 3 e 4 de uma rede de ensino superior, obtendo os seguintes resultados:

Gráfico I - Acompanhamento de entregas das atividades das instituições de ensino 
superior

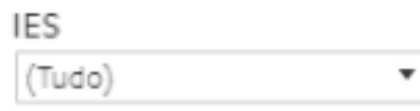

Acompanhamento de entregas EaDL

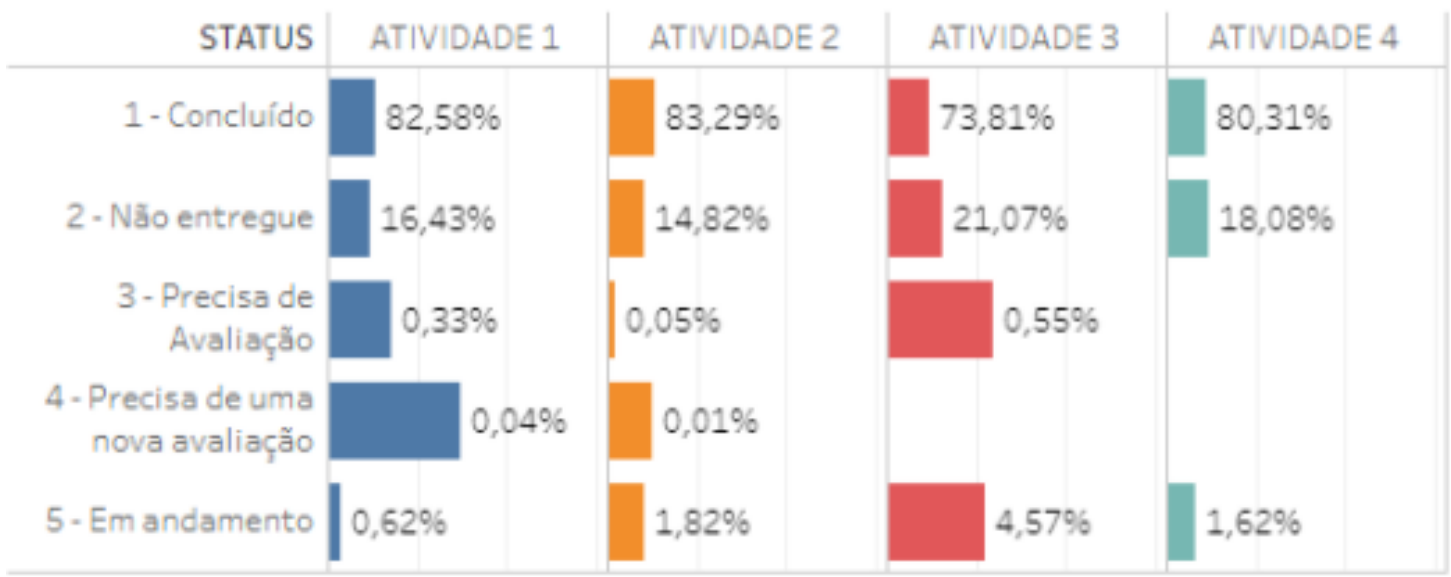

Fonte: Blackboard LMS, 2017.

Considerando que a totalidade das tarefas para cômputo de nota N1 (Atividades 1,2,3 e 4, valendo 2,5 pontos cada) leva em conta a entrega de pelos 3 destas 4 atividades, para garantir os $75 \%$ de presença, e possíveis 7,5 de nota, observa-se que a Atividade 3 , em todas as quatro IES pesquisadas da Rede de ensino, apresenta declínio no nível de participação, sendo muito abaixo dos percentuais apontados nas demais atividades. Assim, observamos que, dadas as políticas estabelecidas nos critérios de avaliação, quando o estudante realiza as Atividades 1 (participação no fórum) e 2 (múltipla escolha), ao chegar na atividade 3 , - dado que é uma questão dissertativa e tida com grau de exigência muito maior do que as demais - este estudante opta pela não realização desta atividade ou não a faz com tanto afinco dentro do esperado, pois irá compensar na próxima e última atividade, a de número 4 . A $4^{\text {a }}$ atividade - também de múltipla escolha e considerada "mais fácil" - é tida pelo estudante como condutor à obtenção dos $75 \%$ de presença mínima por ter feito 3 das 4 atividades, possibilitando que sua nota na N1 seja 7,5 ainda que não tenha feito uma das quatro.

\section{CONSIDERAÇÕES FINAIS}

Com base nas crescentes necessidades das universidades em avaliar seus esforços para melhorar o engajamento dos estudantes, este estudo sugeriu uma leitura de engajamento contextualizado a partir da $3^{\underline{a}}$ atividade avaliativa. As disciplinas, 0 desenvolvimento do paradigma do curso, a motivação do estudante, a experiência do professor, a concepção de ensino e aprendizagem do professor e a interação do tutor 
são apenas alguns dos fatores que podem influenciar o envolvimento dos estudantes.

O estudo analisou como os dados capturados pelos sistemas de gerenciamento de aprendizado podem potencialmente ser usados para medir e informar. O Programa de Permanência Acadêmica (PROPAC) por meio das ações propostas é utilizado para melhorar o engajamento dos estudantes. Dentre esses dados, foram as entregas das atividades 1, 2, 3 e 4 de uma rede de ensino pelo método quantitativo.

Notamos que a entrega dos exercícios tem indicadores próximos em se tratando das atividades 1, 2 e 4; no entanto a atividades 3 descola 8 pontos percentuais para baixo do indicador mais próximo. O percentual das entregas varia para baixo nesta atividade, sendo que o estudante está engajado nas atividades até a passagem de bloco compensada na próxima atividade, a $4^{\underline{a}}$ e última. Podemos observar na atividade 3 quando ocorre o decréscimo, que existem planos de ação de engajamento por parte da IES contatando esses estudantes por meio de whatsapp e telefone, frutos também das ações do Programa de Permanência Acadêmica - PROPAC apontando um processo interventivo como forma de minimizar os impactos negativos do descolamento dos percentuais esperados, promovendo ações efetivamente interativas que além de estimular o estudante, também condicione sua percepção de indivíduo reforçando seu aprendizado e propiciando o sucesso acadêmico.

Este cenário aponta que por meio do PROPAC o estudante direciona seus esforços de engajamento de forma estratégica e compensatória, garantindo a variável da presença obrigatória, e assim, tendo tempo de preparar-se para a prova presencial N2, também de múltipla escolha, que representa $60 \%$ do valor total da nota.

Mais estudos são necessários em relação à conscientização do mercado das próprias instituições de ensino sobre seu trabalho na presença desse público cada vez mais qualificado.

\section{REFERÊNCIAS}

ASSOCIAÇÃO BRASILEIRA DE EDUCAÇÃO A DISTÂNCIA - ABED. Censo EAD.BR. Relatório analítico de ensino a distância no Brasil. 2016

BEER, C. Engajamento de Alunos On-line. 2010. Disponível em: . Acesso em: 22 dez. 2017.

BEHRENS, MA. O paradigma emergente e a prática pedagógica. Petrópolis: Vozes; 
2005.

BULLEN, M. Participação e pensamento crítico no ensino a distância universitário online. International Journal of E-Learning \& Distance Education. 2007. Aug 11;13(2):1-32.

CHEN, P.-S. D., GONYEA, R., \&KUH, G. Aprendizagem à distância. Jornal de educação on-line. 2009. Disponível em:. Acesso em: 04 jan. 2018.

COATES, H. Um modelo de engajamento de estudantes online e geral no campus. Assessment \& Evaluation in Higher Education. 2007 Abr 1;32(2):121-41.

DOUGLAS, I.,ALEMANNE, N. D. Medindo a participação e o esforço do aluno. Conferência Internacional sobre Cognição e Aprendizagem Exploratória na Era Digital. 2007. Algarve, Portugal.

FREIRE, P. Educação como prática de liberdade. 29a ed. Rio de Janeiro: Paz e Terra; 2006.

MINAYO, Maria Cecília de Souza. O desafio do conhecimento: pesquisa qualitativa em saúde. São Paulo: Hucitec, 1993.

REYES, M.R., BRACKETT, M.A., RIVERS, S.E., WHITE, M., \& SALOVEY, P. Clima Emocional da Sala de Aula, Engajamento dos Alunos e Conquistas Acadêmicas. Jornal de Psicologia Educacional. Publicação online avançada. 2012. Doi: 10.1037 / a0027268.

TIMES, M. Criando uma cultura de envolvimento do aluno. 2017. Disponível em: Acesso em: 02 jan. 2018. 